\title{
Valproate-doxorubicin: promising therapy for progressing mesothelioma. A phase II study
}

\author{
A. Scherpereel*,\#,++, T. Berghmans ${ }^{\top,++}$, J.J. Lafitte*,\#, B. Colinet ${ }^{+}$, M. Richez ${ }^{\S}$, \\ Y. Bonduelle ${ }^{f}$, A.P. Meert ${ }^{\dagger}$, X. Dhalluin*, N. Leclercq ${ }^{\ddagger}$, M. Paesmans**, \\ L. Willems ${ }^{\# \#}$ and J.P. Sculier ${ }^{\top}$ for the European Lung Cancer Working Party (ELCWP)
}

ABSTRACT: No treatment is recommended for patients with malignant mesothelioma (MM) failing after first-line cisplatin-based chemotherapy. In vitro data suggested that valproic acid, a histone deacetylase inhibitor (HDACi), had a proapoptotic effect and synergised with doxorubicin to induce apoptosis in MM cells. Our primary end-point was to determine response rate of combined valproic acid and doxorubicin in patients with unresectable MM failing after platinum-based chemotherapy.

Treatment consisted of doxorubicin $\left(60 \mathrm{mg} \cdot \mathrm{m}^{-2}\right)$ plus valproic acid. An interim analysis for response rate was planned after the first 16 registered patients. All the cases were centrally reviewed.

From July 2006 to March 2009, 45 eligible patients with pleural MM were registered. The majority of the patients were male $(73 \%)$, had a performance status (PS) $\geqslant 80(76 \%)$ and an epithelioid subtype (80\%). There were seven partial responses (response rate $16 \%$; $95 \% \mathrm{Cl} 3-$ $25 \%)$, all in patients with PS $80-100$. The best disease control rate was $36 \%(95 \% \mathrm{Cl} 22-51 \%)$. Two toxic deaths were observed (febrile neutropenia and cerebral thrombotic event), both in patients with poor PS (60-70).

Valproic acid, an HDACi, plus doxorubicin appeared an effective chemotherapy regimen in good PS (80-100) patients with refractory or recurrent MM, for which no standard therapy was available.

KEYWORDS: Chemotherapy, doxorubicin, histone deacetylase inhibitors, mesothelioma, valproic acid

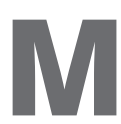
alignant mesothelioma (MM) is a rare malignancy with increasing incidence, due to the large use of asbestos and a poor prognosis. First-line chemotherapy combining cisplatin and pemetrexed is currently the standard care [1] for inoperable patients, having demonstrated improved response rate and survival in comparison with cisplatin alone in a phase III trial [2]. A second randomised study confirmed the activity of the antifolate raltitrexed in MM [3]. Currently, there is no standard second-line therapy for MM [1]. In a phase III trial comparing pemetrexed to palliative care alone, JASSEM et al. [4] demonstrated improved progression-free survival and time to progression without impact on overall survival. Few other studies assessed the effectiveness of chemotherapy as a second-line therapy. Response rates between $10 \%$ and $20 \%$ were noted with doxorubicin $[5,6]$, pemetrexed
[7], pemetrexed plus carboplatine [7], vinorelbine [8] or a combination of cisplatin, mitomycine and irinotecan [9]. As seen from these results, new treatments, including drugs with original activity profile are needed. The 2008 European Respiratory Society (ERS)/European Society of Thoracic Surgeons (ESTS) Task Force on MM management recommended that patients demonstrating prolonged symptomatic and objective response with first-line chemotherapy may be treated again with the same regimen in the event of recurrence. In other cases, inclusion of the patients in clinical trials is encouraged [1].

The purpose of the present phase II study was to evaluate the potentialities of a novel approach based on the concept of gene activation therapy. Our working hypothesis relied on the regulation of cell homeostasis, which is the result of a

\section{AFFILIATIONS}

*Dept of Pulmonary and Thoracic Oncology, CHRU de Lille and University of Lille $\mathrm{II}$, and *INSERM U1019, Centre d'Infection et d'Immunite de Lille, Institut Pasteur de Lille, Lille, France. "Dept of Intensive Care Unit and Thoracic Oncology, Institut Jules Bordet, Centre des Tumeurs de I'Université Libre de Bruxelles (ULB) **Data Centre, Institut Jules Bordet, Centre des Tumeurs de I'Université Libre de Bruxelles ELCWP, Brussels, +Dept of Pneumology, Grand Hôpital de Charleroi, site Saint-Joseph, Gilly, ${ }^{\S}$ Dept of Pneumology, CHR St

Joseph, Warquignies

${ }^{f}$ Dept of Pneumology, CH Peltzer-La Tourelle, Verviers, and

\#\# Gembloux Agro-Bio Tech and Interdisciplinary Cluster for Applied Genoproteomics (GIGA), University of Liège, Liège, Belgium.

+Both authors contributed equally to this work

"A full list of the ELCWP Study Group members and their affiliations can be found in the

Acknowledgements section.

\section{CORRESPONDENCE}

T. Berghmans, Institut Jules Bordet, Rue Héger-Bordet, 1, 1000 Brussels, Belgium

E-mail: thierry.berghmans@

bordet.be

Received:

March 092010

Accepted after revision:

April 292010

First published online:

June 072010

European Respiratory Journal Print ISSN 0903-1936 Online ISSN 1399-3003 
clinical balance between cell proliferation and death. A resistance to apoptosis is among the key mechanisms described in the pathogenesis of MM [10]. Our hypothesis was that the lack of apoptosis is the result of cell quiescence, correlating with an absence of gene expression of some apoptotic molecules. We proposed to relieve this silencing block by using a histone deacetylase inhibitor (HDACi). HDACi have a potential role in the regulation of gene expression, induction of cell death, apoptosis, cell cycle arrest of cancer cells, and inhibition of angiogenesis, motility and invasion of tumour cells by altering the acetylation status of chromatin and other non-histone proteins [11, 12]. HDACi exert profound modifications of the cell biology and some of these molecules have been proposed as potential anticancer agents [13].

HDACi include a variety of compounds belonging to several structural classes: hydroxamic acids (trichostatin A, suberoylanilide hydroxamic acid or vorinostat); cyclic peptides (trapoxin and depsipeptide), benzamides (MS-27-275) and short-chain fatty acids (butyric acid and valproic acid). Presently, the molecular basis of response to HDACi is not fully understood. Valproic acid, an old anti-convulsant drug widely used in patients with epilepsy, exhibited HDACi properties at therapeutic blood concentrations [14] without documented negative interactions with doxorubicin [15]. Valproic acid has demonstrated interesting inhibiting activity on different cell lines and tumour xenografts in mice. Growth inhibition and apoptosis were reported in haematological and solid tumours [16-22]. We showed that valproic acid increases the apoptosis induced by a combination of cisplatin and pemetrexed in MM cell lines and in tumour cells from patient's biopsies [23]. More recently, VANDERMEERS et al. also found that valproic acid synergised with doxorubicin to induce apoptosis in MM cells (F. Vandermeers, Gembloux Agro-Bio Tech and Interdisciplinary Cluster for Applied Genoproteomics (GIGA), University of Liège, Liège, Belgium; personal communication).

Valproic acid was tested in a few phase I-II studies in acute leukaemia and myelodysplastic syndrome, in combination with chemotherapeutic agents [12]. Several studies were performed in solid tumours in a limited number of patients, either alone or in combination with chemotherapy [24-27]. None of these studies included MM patients. Valproic acid was administered according to different schedules, most frequently orally at doses used for the treatment of epilepsy, either continuously during the whole duration of chemotherapy or during a specified time of the chemotherapy cycle. In two phase I studies performed in solid tumours, valproic acid was given intravenously at a very high dosage, up to 120 or $160 \mathrm{mg} \cdot \mathrm{kg}^{-1}[24,25]$.

The aim of the present study was to test the combination of valproic acid and doxorubicin in patients with refractory or recurrent MM after standard first-line chemotherapy.

\section{MATERIAL AND METHODS}

This phase II study is an academic trial (EUDRACT 2006001443-63) with the protocol available on the European Lung Cancer Working Party website (ELCWP); www.elcwp.org and Clinical Trials.gov (www.clinicaltrials.gov).

\section{Selection criteria}

To be eligible, patients had to present with histologically confirmed unresectable or inoperable MM failing after at least one prior chemotherapy regimen including platinum derivatives (cisplatin or carboplatin), whatever the response to the first-line treatment, and at least one evaluable or measurable lesion. Other eligibility criteria included Karnofsky performance status (PS) $\geqslant 60$, and good renal (serum creatinine level $\leqslant 1.5 \mathrm{mg} \cdot \mathrm{dL}^{-1}$ ), hepatic (serum bilirubin level $\leqslant 1.5 \mathrm{mg} \cdot \mathrm{dL}^{-1}$ and aspartate aminotransferase/alanine aminotransferase less than twice the normal range) and haematological (neutrophil count $\geqslant 2,000$ per $\mu \mathrm{L}$ and platelet count $\geqslant 100,000$ per $\mu \mathrm{L}$ ) functions. Coagulation tests (activated partial thromboplastin time, partial thromboplastin time and prothrombin time) and fibrinogen had to be in the normal ranges. Patients had to be accessible for participating in the detailed follow-up of the protocol and to have provided written informed consent.

Ineligibility criteria were the following: recent ( $<3$ months) myocardial infarction, congestive heart failure (ejection fraction of the left ventricle $<50 \%$ ) or cardiac arrhythmia requiring medical treatment; uncontrolled infectious disease or other serious medical or psychiatric illness precluding adherence to the study protocol; prior history of malignancy except nonmelanoma skin cancer or in situ carcinoma of the cervix and "cured" malignant tumour (>5-yr disease-free interval); active epilepsy needing a specific treatment; concomitant treatment with monoamine-oxidase inhibitor, carbamazepine, mefloquine, phenobarbital, primidone, phenytoïn, lamotrigine, zidovudine; history of prior HIV infection; pregnancy or refusal to use active contraception; known allergy to valproic acid and/or doxorubicin; previous treatment with anthracyclin derivatives.

\section{Investigations}

Initial work-up included clinical evaluation completed by weight, height, surface area and record of Karnofsky PS, complete blood sampling, electrocardiogram, chest radiograph and computed tomography scan, isotopic or echographic left ventricular fraction assessment. Blood counts were performed weekly. Blood chemistries including valproic acid measurement, chest radiograph and clinical examination were repeated before each new course. An evaluation after each three courses of chemotherapy was performed with the same tests as during the initial work-up and repeated every three cycles. After treatment completion, patients were followed every 2 months with clinical evaluation, chest radiograph and biological tests.

\section{Treatment}

After central registration at the ELCWP data centre, eligible patients were treated with oral valproic acid in order to obtain serum concentrations in the range of the recommended values for the treatment of epilepsy $\left(50-100 \mu \mathrm{g} \cdot \mathrm{mL}^{-1}\right)$, at the dose of 20-30 $\mathrm{mg} \cdot \mathrm{kg}^{-1} \cdot \mathrm{day}^{-1}$ during meals. When stable therapeutic concentrations were obtained (generally after 1-2 weeks), patients were treated with doxorubicin at $60 \mathrm{mg} \cdot \mathrm{m}^{-2}$ as a short intravenous infusion every 3 weeks and valproic acid continued during the whole treatment.

Courses were repeated every 3-4 weeks, as soon as haematological (neutrophils $>1,500$ per $\mathrm{mm}^{3}$ and platelets $>100,000$ per $\mathrm{mm}^{3}$ ) function had recovered. If myelosuppression 
persisted on day 36, the patient went off treatment. In absence of progression, treatment was continued until the best response was achieved, or until there was an unacceptable toxicity or cumulative dose of doxorubicin $>500 \mathrm{mg} \cdot \mathrm{m}^{-2}$.

During the whole treatment, the following adaptations of doses were planned. If neutrophils nadir was $<500$ per $\mathrm{mm}^{3}$ and/or platelets $<25,000$ per $\mathrm{mm}^{3}$, the dose of doxorubicin was reduced to $75 \%$ for the next course. In the case of World Health Organization (WHO) grade 3 or 4 cardiac dysrhythmias, treatment was stopped; in the case of WHO grade 2, treatment continuation was discussed on a case by case basis. Treatment was stopped if a reduction of the left ventricular fraction of $>10 \%$ from the baseline was observed or a reduction below the absolute value of $50 \%$. In the case of WHO grade $\geqslant 3$ stomatitis, the dose of doxorubicin was reduced to $75 \%$ for the next course. In the case of WHO grade $\geqslant 2$ skin toxicity attributable to valproic acid, it was stopped and doxorubicin continued at the same dosage. For any other grade $\geqslant 3 \mathrm{WHO}$ toxicity, if doxorubicin was responsible, the whole treatment was stopped, except for alopecia, nausea and vomiting or anaemia; if valproic acid was responsible, it was stopped and doxorubicin continued.

If plasma valproic acid was outside of the therapeutic range, oral doses were adapted in order to obtain serum concentrations between $50-100 \mu \mathrm{g} \cdot \mathrm{mL}^{-1}$. In cases of overdose, valproic acid was stopped and reintroduced only if all adverse events had resolved.

\section{Criteria of evaluation}

Response was evaluated after every three courses according to the WHO criteria. Response status, as well as the initial tumour, node, metastasis stage, was assessed during regular meetings of the group by at least three independent observers. Patients with early progression or death prior to evaluation due to malignant disease or toxicity, and treatment cessation due to toxicity were considered as treatment failures. WHO criteria were used to assess toxicity.

Duration of response was calculated from the first date of response documentation until the date of first observation of progressive disease or death without documented progression in patients with an objective response. Progression-free survival was defined as the period between the day of registration and the date of first progression or death. Survival was dated from the day of registration.

\section{Statistical considerations}

Sample size evaluation has been performed considering, as primary end-point, the antitumoural response and making use of the two-stage optimal design of SIMON [28]. In this secondline setting, we considered that a response rate reaching $15 \%$ was of clinical value and should be detected, if true, with a statistical power of $90 \%(\beta=10 \%)$. Conversely, we considered that a theoretical response rate $\leqslant 2 \%$ should lead to the rejection of the tested combination of doxorubicin and valproic acid with a probability of $95 \%(\alpha=5 \%)$. On the basis of these assumptions, 16 evaluable patients needed to be registered in the trial in the first step. Early closure should occur if there was no response among these first patients. Otherwise, inclusion of patients had to be pursued until a total sample size of 41 patients. After this second step, the tested treatment had to be judged as warranting further research if at least three patients responded to treatment.

Univariate analysis for looking at factors predictive of response to the tested regimen were performed using Fisher exact tests, Chi-squared tests for categorical covariates or using logistic regression for a continuous covariate. Univariate analysis for survival was performed using Kaplan-Meier estimates and comparison of survival distributions for possible prognostic factors using log-rank tests. Multivariate analysis was planned to use forward methods for selection of covariates and required to be performed the identification of at least two covariates associated with a p-value of $<0.20$.

\section{RESULTS}

Between July 2006 and March 2009, 46 consecutive patients were registered. One patient was deemed ineligible because of wrong histology. Characteristics of the 45 eligible patients are depicted in table 1 . The majority of the patients were male $(73 \%)$, had a good PS of $\geqslant 80$ on the Karnofsky scale $(76 \%)$ and presented with epithelial histological subtype (80\%). The initial localisation of malignant mesothelioma was pleural in all cases. Previous first-line chemotherapy included the following regimens: cisplatin $(n=37)$ or carboplatin $(n=4)$ and

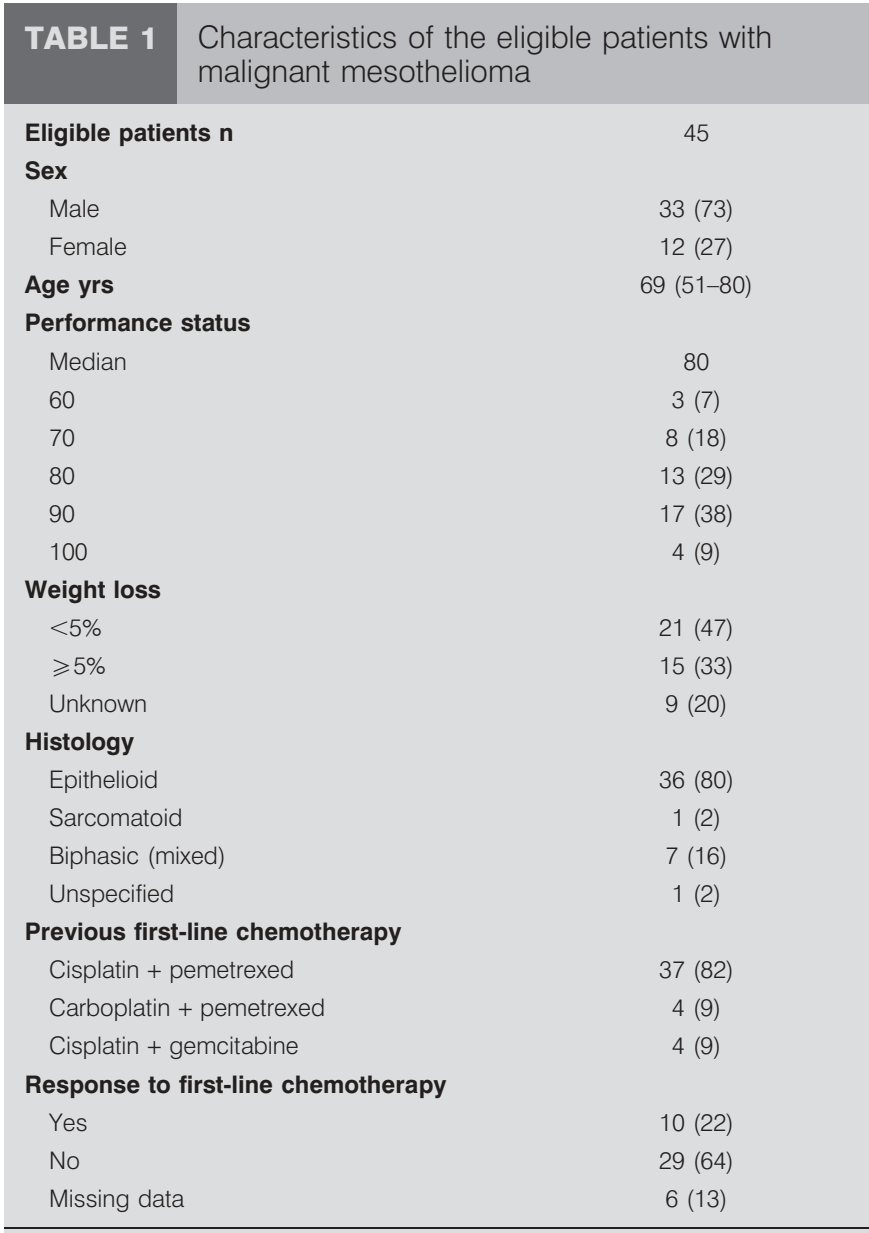

Data are presented as $\mathrm{n}(\%)$ or median (range), unless otherwise stated. 
pemetrexed, cisplatin and gemcitabine $(n=4)$. Second- and third-line regimens included cisplatin $(n=2)$ or carboplatin $(n=1)$ and pemetrexed, pemetrexed alone $(n=1)$, docetaxel plus gemcitabine $(n=1)$, or vorinostat $(n=4)$. At the time of analysis (September 2009) 35 patients were dead. Median follow-up for living patients was 12.4 months.

Two patients were unassessable for response because of treatment refusal before the first course of chemotherapy and loss to follow-up before radiological evaluation. Overall, 150 chemotherapy cycles were administered during the study, ranging from one to six per patient. The number of patients receiving one, two, three and six cycles was 10, 7, 14 and 14, respectively. Three partial responses were observed during the first step of the study, allowing further inclusions. Response rate at three cycles was $13 \%$ (intent-to-treat analysis). Best response rate was seven (16\%) out of 45 (95\% CI 3-25\%). All the seven responding patients presented with good PS of 80 $(n=1), 90(n=5)$ or $100(n=1)$. Five had epitheloid histological subtype of $\mathrm{MM}$ and three were male. Best disease control rate (partial response plus stable disease) was 36\% (95\% CI 22-51\%) (table 2). Actuarial median response duration was 11.8 months with three patients still alive without documentation of progression at 8,11 and 26 months after first documentation of response. Univariate analyses did not find any statistically significant factor predicting response to chemotherapy, although all objective responses were documented in good PS patients (table 3 ).

Median progression-free survival was 2.5 months (95\% CI 2.03.0 months) (fig. 1). At $1 \mathrm{yr}, 25 \%$ of patients were alive and $14 \%$ patients were alive without progression. Median survival was 6.7 months (95\% CI 4.9-8.5 months) (fig. 1). In univariate analysis, only PS was a statistically significant prognostic factor for survival (table 4). Survival was also assessed according to response status using a landmark at 3.88 months (maximal time elapsed for having assessed as responder a patient after three courses of chemotherapy). Median survival time for responding patients was 16.7 months after the landmark. Among the 24 nonresponders alive at the landmark, median survival after the landmark was 4.5 months. The difference was statistically significant $(p=0.03)$.

As expected, the main toxicities were leukopenia and neutropenia. Two toxic deaths, both in poor PS patients, were

\begin{tabular}{lcc}
\hline TABLE 2 & $\begin{array}{l}\text { Response rates at three and six cycles in } \\
\text { patients with malignant pleural mesothelioma } \\
\text { treated with doxorubicin and valproic acid }\end{array}$ \\
& At three cycles & At six cycles \\
\hline Partial response & $6(13)$ & $7(16)$ \\
Stable disease & $10(22)$ & $4(9)$ \\
Progression & $20(44)$ & $25(56)$ \\
Early death by cancer & $1(2)$ & $1(2)$ \\
Toxic death & $2(4)$ & $2(4)$ \\
Stop for high toxicity & $4(9)$ & $4(9)$ \\
Unassessable & $2(4)$ & $2(4)$ \\
\hline
\end{tabular}

Data are presented as $n(\%)$.

\begin{tabular}{|c|c|c|c|c|}
\hline \multirow[t]{2}{*}{ TABLE 3} & \multicolumn{4}{|c|}{$\begin{array}{l}\text { Univariate analyses of factors predicting } \\
\text { response in patients treated with doxorubicin } \\
\text { and valproic acid }\end{array}$} \\
\hline & & Patients n & Response $\mathrm{n}$ & $p$-value \\
\hline \multicolumn{5}{|c|}{ Performance status } \\
\hline $60-70$ & & 11 & 0 & 0.16 \\
\hline $80-100$ & & 34 & 7 & \\
\hline \multicolumn{5}{|l|}{ Sex } \\
\hline Male & & 33 & 3 & 0.07 \\
\hline Female & & 12 & 4 & \\
\hline $\begin{array}{l}\text { Age yrs (cor } \\
\text { variable) }\end{array}$ & inuous & & & 0.19 \\
\hline \multicolumn{5}{|l|}{ Histology } \\
\hline Epitheloid & & 36 & 5 & 0.69 \\
\hline Other & & 9 & 2 & \\
\hline \multicolumn{5}{|c|}{$\begin{array}{l}\text { Response to first- } \\
\text { line chemotherapy }\end{array}$} \\
\hline Yes & & 10 & 2 & 0.29 \\
\hline No & & 29 & 5 & \\
\hline \multicolumn{5}{|l|}{ Stage } \\
\hline IV & & 13 & 3 & 0.39 \\
\hline$|-|||$ & & 32 & 4 & \\
\hline
\end{tabular}

documented: one febrile neutropenia and one cerebral thrombotic event. One patient developed grade IV cardiac failure. Highest toxicity per patient during the whole course of treatment is reported in table 5 .

\section{DISCUSSION}

Consistent with previous experimental data ([23] and VANDERMEERS et al. (F. Vandermeers, GIGA, University of Liège; personal communication), the combination of valproic acid, a HDACi, and doxorubicin appears as an effective chemotherapy regimen in good PS (80-100) patients with refractory or recurrent $\mathrm{MM}$ after a first-line cisplatin-based



FIGURE 1. Survival and progression-free survival curves of patients treated with doxorubicin and valproic acid. __ : overall survival (OS); - - - -: progressionfree survival (PFS). 


\begin{tabular}{|c|c|c|c|c|}
\hline \multirow[t]{2}{*}{ TABLE 4} & \multicolumn{4}{|c|}{$\begin{array}{l}\text { Univariate analyses of prognostic factors for } \\
\text { survival in patients treated with doxorubicin and } \\
\text { valproic acid }\end{array}$} \\
\hline & & Patients n & Survival months & p-value \\
\hline \multicolumn{5}{|c|}{ Performance status } \\
\hline $60-70$ & & 11 & 1.5 & $<0.001$ \\
\hline $80-100$ & & 34 & 8.8 & \\
\hline \multicolumn{5}{|l|}{ Sex } \\
\hline Male & & 33 & 6.9 & 0.63 \\
\hline Female & & 12 & 3.5 & \\
\hline $\begin{array}{l}\text { Age yrs (cor } \\
\text { variable) }\end{array}$ & inuous & & & 0.27 \\
\hline \multicolumn{5}{|l|}{ Histology } \\
\hline Epitheloid & & 36 & 6.9 & 0.44 \\
\hline Other & & 9 & 5.5 & \\
\hline \multicolumn{5}{|c|}{$\begin{array}{l}\text { Response to first- } \\
\text { line chemotherapy }\end{array}$} \\
\hline Yes & & 10 & 5.9 & 0.39 \\
\hline No & & 29 & 6.9 & \\
\hline \multicolumn{5}{|l|}{ Stage } \\
\hline IV & & 13 & 6.2 & 0.97 \\
\hline I-III & & 32 & 6.7 & \\
\hline
\end{tabular}

chemotherapy, in accordance with the study statistical hypothesis. Despite a recruitment including some MM patients with poor PS, ranging from 60-100, we observed an interesting response rate of $16 \%$ and a best disease control rate of $36 \%$ when treating patients with valproic acid plus doxorubicin, resulting in a longer survival of responding patients compared to nonresponding subjects from a landmark at 3.88 months.

In fact, no drug has been validated for second-line chemotherapy for MM patients, leading the ERS/ESTS experts to recommend that these patients should rather be proposed to enter into clinical trials [1]. Among the different investigated agents, HDACi demonstrated in vitro and in clinical trials some potential anticancer activity in haematological and solid tumours [12]. In mesothelioma, the value of HDACi vorinostat and panobinostat were assessed in animal models [29, 30]. Vorinostat monotherapy has been tested so far in patients with MM failing after standard first-line chemotherapy. In a phase I trial [30], two patients out of 13 demonstrated a partial response. The results of a phase II trial (oral vorinostat versus placebo) are not published and a placebo-controlled randomised phase III study of second-line oral vorinostat is ongoing. Another HDACi monotherapy with belinostat (PXD101) showed no antitumour activity in MM, with two patients among 13 presenting with a stable disease [31]. Thus, our study is the first to report responses obtained with that therapeutic approach in MM.

VANDERMEERS et al. (F. Vandermeers, GIGA, University of Liège; personal communication) observed in vitro in MM cells that valproic acid can synergise with doxorubicin to induce apoptosis. Other authors showed similar results in anaplastic thyroid cancer cells [22]. It was suggested that the antitumour activity of doxorubicin, relying on its binding to DNA and the inhibition of topoisomerase II, is enhanced through histone

\begin{tabular}{|c|c|c|c|c|c|}
\hline \multirow{2}{*}{$\begin{array}{l}\text { TABLE } 5 \\
\text { Toxicity }\end{array}$} & \multicolumn{5}{|c|}{$\begin{array}{l}\text { Highest toxicity during the whole treatment } \\
\text { among } 45 \text { patients receiving at least one cycle of } \\
\text { chemotherapy }\end{array}$} \\
\hline & 0 & 1 & II & III & IV \\
\hline Leukopenia & $8(18)$ & $5(11)$ & $15(33)$ & $11(24)$ & $3(7)$ \\
\hline Neutropenia & $4(9)$ & $4(9)$ & $8(18)$ & $11(24)$ & $15(33)$ \\
\hline Thrombopenia & $30(67)$ & $3(7)$ & $7(16)$ & $2(4)$ & \\
\hline Nausea & $19(42)$ & $18(40)$ & $2(4)$ & $1(2)$ & \\
\hline Diarrhoea & $30(67)$ & $8(18)$ & $2(4)$ & & \\
\hline Stomatitis & $34(76)$ & $2(4)$ & $4(9)$ & & \\
\hline Skin & $36(80)$ & $2(4)$ & $1(2)$ & $1(2)$ & \\
\hline Infection & $32(71)$ & $4(9)$ & $4(9)$ & & \\
\hline Bleeding & $39(87)$ & $1(2)$ & & & \\
\hline $\begin{array}{l}\text { Neurological } \\
\text { (encephalo- } \\
\text { pathy) }\end{array}$ & $37(82)$ & $2(4)$ & $1(2)$ & & \\
\hline $\begin{array}{l}\text { Neurological } \\
\text { (peripheral) }\end{array}$ & $34(76)$ & $5(11)$ & $1(2)$ & & \\
\hline Constipation & $36(80)$ & $2(4)$ & $1(2)$ & & \\
\hline Respiratory & $28(62)$ & & $11(24)$ & $1(2)$ & \\
\hline Cardiac & $36(80)$ & $1(2)$ & $2(4)$ & $1(2)$ & $1(2)$ \\
\hline Alopecia & $15(33)$ & $6(13)$ & $6(13)$ & $14(31)$ & \\
\hline Loss of hearing & $36(80)$ & $4(9)$ & $1(2)$ & & \\
\hline Renal & $41(91)$ & $2(4)$ & & & \\
\hline $\begin{array}{l}\text { Febrile neutro- } \\
\text { penia }\end{array}$ & $43(96)$ & & & $1(2)$ & $1(2)$ \\
\hline Vascular & $42(93)$ & & 1 non fata & 1 fatal (1) & \\
\hline Other & $35(78)$ & $4(9)$ & $4(9)$ & $2(4)$ & \\
\hline
\end{tabular}

Data are presented as n (\%)

acetylation and increased apoptosis as shown by the increased caspase 3 activation and the enhancement of doxorubicininduced G2 cell cycle arrest [32]. We observed an interesting response rate with the combination of valproic acid and doxorubicin that has not been previously reported with doxorubicin alone in two previous small studies; one patient among 11 and none among six showed partial response with second-line doxorubicin alone [5, 6]. Importantly, all the seven responding patients in our study presented with good PS (PS 80-100) (Eastern Cooperative Oncology Group PS 0-1). Consistently, PS was the only statistically significant prognostic factor for survival. Patients with poor PS at inclusion (PS 60-70) did not respond to treatment and showed severe toxicities (febrile neutropenia and thrombotic event). If we failed to detect PS as a factor with a statistically significant association with response to the tested regimen, it had a prognostic value for overall survival.

Neurocognitive impairment is a common side-effect reported in phase I-II studies with valproic acid. It consisted of confusion, somnolence, dizziness, hallucination or encephalopathy. It could be observed at therapeutic serum concentrations but was increased with higher doses of valproic acid [24, 25]. In contrast to previous studies, we did not observe grade 3-4 neurological toxicity. Other toxicities are difficult to compare with the previous studies, chemotherapy and population being noticeably different. A recent phase I/II trial 
assessed valproic acid given at high intravenous dosages during 3 days in combination with epirubicin or a combination of 5-fluorouracil, epirubicin and cyclophosphamide in 44 patients with solid tumours [25]. Several partial responses were obtained. Outside of valproic acid associated neurovestibular disturbance, the most frequent side-effect was epirubicin-induced myelosuppression, as we found in the present study. Thus, in our study as in the literature, the HDACi valproic acid had limited side-effects and exhibited antitumour activity when combined with chemotherapy, which was responsible for more severe toxicities.

In conclusion, this study suggests that doxorubicin and valproic acid appear to be an effective chemotherapy regimen in good PS (80-100) patients with refractory or recurrent MM after first-line cisplatin-based chemotherapy. However, these results need confirmation in a randomised trial, which is the only way to validate the effectiveness of this chemotherapy regimen. It is noteworthy that this quite efficient regimen combines old but very cheap drugs, as MM incidence is expected to increase in the next decades in the developing countries still using asbestos without strict regulation.

Future directions include the search for clinical and biological markers to predict the response to HDACi and the prognosis of patients, the development of new HDACi and/or isoforms of previous HDACi with less toxicity than valproic acid or vorinostat but more antitumour effect, and the use of HDACi (valproic acid) in combination with first-line chemotherapy (cisplatin plus pemetrexed) in MM patients.

\section{SUPPORT STATEMENT}

This work was supported by the Télévie and the "Fonds National de la Recherche Scientifique" (FNRS) and by the "RESPIR" association (Lille, France). L. Willems is research director of the FNRS.

\section{CLINICAL TRIAL}

This study is registered at ClinicalTrials.gov identifier number NCT00634205.

\section{STATEMENT OF INTEREST}

None declared.

\section{ACKNOWLEDGEMENTS}

ELCWP Study Group participating institutions: Institut Jules Bordet, Brussels, Belgium (J.P. Sculier, T. Berghmans, C. Mascaux, A.P. Meert, M. Paesmans and N. Leclercq); Hôpital Albert Calmette, CHRU of Lille, Lille, France (J.J. Lafitte, A. Scherpereel, X. Dhalluin, B. Chahine and E. Wasiliewski); Grand Hôpital de Charleroi, site Saint-Joseph, Gilly, Belgium (B. Colinet); CHR St-Joseph, Warquignies, Belgium (M. Richez and P.E. Baugnée); CH Peltzer-La Tourelle, Verviers, Belgium (Y. Bonduelle and I. Louviaux); Hôpital Civil de Charleroi, Charleroi, Belgium (J. Lecomte); Hôpital Ambroise Paré, Mons, Belgium (P. Wackenier and S. Holbrechts).

\section{REFERENCES}

1 Scherpereel A, Astoul P, Baas P, et al. Guidelines of the European Respiratory Society and the European Society of Thoracic Surgeons for management of malignant pleural mesothelioma. Eur Respir J 2010; 35: 479-495.

2 Vogelzang NJ, Rusthoven JJ, Symanowski J, et al. Phase III study of pemetrexed in combination with cisplatin versus cisplatin alone in patients with malignant pleural mesothelioma. J Clin Oncol 2003; 21: 2636-2644.

3 van Meerbeeck JP, Gaafar R, Manegold C, et al. Randomized phase III study of cisplatin with or without raltitrexed in patients with malignant pleural mesothelioma: an intergroup study of the European organisation for research and treatment of cancer lung cancer group and the National Cancer Institute of Canada. J Clin Oncol 2005; 23: 6881-6889.

4 Jassem J, Ramlau R, Santoro A, et al. Phase III trial of pemetrexed plus best supportive care compared with best supportive care in previously treated patients with advanced malignant pleural mesothelioma. J Clin Oncol 2008; 26: 1698-1704.

5 Harvey VJ, Slevin ML, Ponder BA, et al. Chemotherapy of diffuse malignant mesothelioma. Phase II trials of single-agent 5-fluorouracil and adriamycin. Cancer 1984; 54: 961-964.

6 Sorensen PG, Bach F, Bork E, et al. Randomized trial of doxorubicin versus cyclophosphamide in diffuse malignant pleural mesothelioma. Cancer Treat Rep 1985; 69: 1431-1432.

7 Sorensen JB, Sundstrom S, Perell K, et al. Pemetrexed as secondline treatment in malignant pleural mesothelioma after platinumbased first-line treatment. J Thorac Oncol 2007; 2: 147-152.

8 Stebbing J, Powles T, McPherson K, et al. The efficacy and safety of weekly vinorelbine in relapsed malignant pleural mesothelioma. Lung Cancer 2009; 63: 94-97.

9 Fennell DA, Steele JP, Shamash J, et al. Efficacy and safety of firstor second-line irinotecan, cisplatin, and mitomycin in mesothelioma. Cancer 2007; 109: 93-99.

10 Narasimhan SR, Yang L, Gerwin BI, et al. Resistance of pleural mesothelioma cell lines to apoptosis: relation to expression of Bcl-2 and Bax. Am J Physiol 1998; 275: L165-L171.

11 Ma X, Ezzeldin HH, Diasio RB. Histone deacetylase inhibitors: current status and overview of recent clinical trials. Drugs 2009; 69: 1911-1934.

12 Stimson L, Wood V, Khan O, et al. HDAC inhibitor-based therapies and haematological malignancy. Ann Oncol 2009; 20: 1293-1302.

13 Marks PA, Richon VM, Breslow R, et al. Histone deacetylase inhibitors as new cancer drugs. Curr Opin Oncol 2001; 13: 477-483.

14 Gottlicher M, Minucci S, Zhu P, et al. Valproic acid defines a novel class of HDAC inhibitors inducing differentiation of transformed cells. EMBO J 2001; 20: 6969-6978.

15 Vecht CJ, Wagner GL, Wilms EB. Interactions between antiepileptic and chemotherapeutic drugs. Lancet Neurol 2003; 2: 404-409.

16 Knupfer MM, Pulzer F, Schindler I, et al. Different effects of valproic acid on proliferation and migration of malignant glioma cells in vitro. Anticancer Res 2001; 21: 347-351.

17 Feng WH, Kenney SC. Valproic acid enhances the efficacy of chemotherapy in EBV-positive tumors by increasing lytic viral gene expression. Cancer Res 2006; 66: 8762-8769.

18 Friedmann I, Atmaca A, Chow KU, et al. Synergistic effects of valproic acid and mitomycin $C$ in adenocarcinoma cell lines and fresh tumor cells of patients with colon cancer. J Chemother 2006; 18: 415-420.

19 Catalano MG, Poli R, Pugliese M, et al. Valproic acid enhances tubulin acetylation and apoptotic activity of paclitaxel on anaplastic thyroid cancer cell lines. Endocr Relat Cancer 2007; 14: 839-845.

20 Sakajiri S, Kumagai T, Kawamata N, et al. Histone deacetylase inhibitors profoundly decrease proliferation of human lymphoid cancer cell lines. Exp Hematol 2005; 33: 53-61.

21 Kaiser M, Zavrski I, Sterz J, et al. The effects of the histone deacetylase inhibitor valproic acid on cell cycle, growth suppression and apoptosis in multiple myeloma. Haematologica 2006; 91: 248-251.

22 Paik PK, Krug LM. Histone deacetylase inhibitors in malignant pleural mesothelioma: preclinical rationale and clinical trials. J Thorac Oncol 2010; 5: 275-279. 
23 Vandermeers F, Hubert P, Delvenne P, et al. Valproate, in combination with pemetrexed and cisplatin, provides additional efficacy to the treatment of malignant mesothelioma. Clin Cancer Res 2009; 15: 2818-2828.

24 Atmaca A, Al-Batran SE, Maurer A, et al. Valproic acid (VPA) in patients with refractory advanced cancer: a dose escalating phase I clinical trial. Br J Cancer 2007; 97: 177-182.

25 Munster P, Marchion D, Bicaku E, et al. Clinical and biological effects of valproic acid as a histone deacetylase inhibitor on tumor and surrogate tissues: phase I/II trial of valproic acid and epirubicin/FEC. Clin Cancer Res 2009; 15: 2488-2496.

26 Chavez-Blanco A, Segura-Pacheco B, Perez-Cardenas E, et al. Histone acetylation and histone deacetylase activity of magnesium valproate in tumor and peripheral blood of patients with cervical cancer. A phase I study. Mol Cancer 2005; 4: 22.

27 Rocca A, Minucci S, Tosti G, et al. A phase I-II study of the histone deacetylase inhibitor valproic acid plus chemoimmunotherapy in patients with advanced melanoma. Br J Cancer 2009; 100: 28-36.
28 Simon R. Optimal two-stage designs for phase II clinical trials. Control Clin Trials 1989; 10: 1-10.

29 Crisanti MC, Wallace AF, Kapoor V, et al. The HDAC inhibitor panobinostat (LBH589) inhibits mesothelioma and lung cancer cells in vitro and in vivo with particular efficacy for small cell lung cancer. Mol Cancer Ther 2009; 8: 2221-2231.

30 Krug LM, Curley T, Schwartz L, et al. Potential role of histone deacetylase inhibitors in mesothelioma: clinical experience with suberoylanilide hydroxamic acid. Clin Lung Cancer 2006; 7: 257-261.

31 Ramalingam SS, Belani CP, Ruel C, et al. Phase II study of belinostat (PXD101), a histone deacetylase inhibitor, for second line therapy of advanced malignant pleural mesothelioma. J Thorac Oncol 2009; 4: 97-101.

32 Blaheta RA, Michaelis M, Natsheh I, et al. Valproic acid inhibits adhesion of vincristine- and cisplatin-resistant neuroblastoma tumour cells to endothelium. Br J Cancer 2007; 96 : 1699-1706. 